\title{
COMPARATIVE STUDY BETWEEN TRADITIONAL AND STAPLED GASTROINTESTINAL ANASTOMOSIS
}

\author{
By
Ahmed Abd El-Aziz Abd El-Ghaffar, Waleed Ra'fat Abd El-Aaty, and Hossam Mohamed Badry Bastawi \\ Department of General Surgery, Faculty of Medicine, Al-Azhar University \\ *Corresponding Author: Hossam Mohamed Badry Bastawi, \\ E-Mail: Hossam.Bastawi@ hotmail.com, Mobile: (+20) 01007525369
}

\begin{abstract}
Background: Intestinal anastomosis is a surgical procedure performed to establish communication between two formerly distant portions of the intestine. This procedure restores intestinal continuity after removal of a pathologic condition affecting the bowel. Intestinal anastomosis is one of the most commonly performed surgical procedures, especially in the emergency setting, and is also commonly performed in the elective setting when resections are carried out for benign or malignant lesions of the gastrointestinal (GI) tract.
\end{abstract}

Objective: The aim of this work was to compare single layer, double layers and stapler intestinal anastomosis (Stomach, Stomach to small, small to small, small to large, large to large) in abdominal procedures and to evaluate the effectiveness of these procedures as regards to its integrity and complications including leakage.

Patients and Methods: Prospective study on 50 patients presented with symptoms and signs suggestive for gastric operations, intestinal surgeries, resection and anastomosis according to inclusion and exclusion criteria. Cases were selected from Al-Azhar University Hospitals and Public Health Hospitals from March 2018 till June 2019.

Results: There were high statistically significance between two groups in intra-operative bleeding, time and cost of operation as 23 patients of stapled group suffered minimal to mild bleeding, high operation cost and less time of procedure while 27 patients suffered minimal to moderate intra-operative bleeding, lower operation cost and longer procedure time. The analysis showed high significance between two groups in postoperative oral nutrition and discharge from hospital as patients underwent stapled anastomosis were allowed for oral nutrition 8 to 24 hours postoperatively and were discharged after 1 to 3 days, while patients underwent traditional anastomosis were allowed for nutrition after 5 to 7 days postoperatively and were discharged after 5 to 10 days.

Conclusion: Stapled gastrointestinal anastomosis consumes lesser time at operation room, less intraoperative bleeding, early recovery and oral nutrition of patients, but has higher cost. Traditional gastrointestinal anastomosis consumes longer time at operation room, relatively more intraoperative bleeding, late recovery and oral nutrition of patients, but has lower cost. Both types of gastrointestinal anastomosis has the same postoperative co-morbidities.

Keywords: Gastrointestinal anastomosis, hand-sewn, Stapled. 


\section{INTRODUCTION}

The outcome of patients who undergo gastrointestinal tract surgery varies greatly. Factors such as the patient's age and comorbidities, the complexity of the surgical procedure and the management of postoperative recovery influence the outcome (Ghaferi et al, 2009)

Intestinal anastomosis is a surgical procedure performed to establish communication between two formerly distant portions of the intestine. This procedure restores intestinal continuity after removal of a pathologic condition affecting the bowel. Intestinal anastomosis is one of the most commonly performed surgical procedures, especially in the emergency setting, and is also commonly performed in the elective setting when resections are carried out for benign or malignant lesions of the gastrointestinal (GI) tract (KaidarPerson et al., 2008)

Intestinal anastomosis can be performed by means of a hand sewn technique that uses absorbable or non-absorbable sutures or by means of stapling. The former is the more commonly used option because of the availability and affordability of suture materials and the wide familiarity with the procedure. The increased availability of stapling devices for intestinal anastomosis has provided an alternative option for performing a rapid anastomosis. Higher cost, limited availability, and less familiarity are the main drawbacks of these devices (Bae et al., 2010)

There are different types of Stapler used in gastrointestinal surgeries; a linear stapler is used in Gastrectomy and small bowel to bowel anastomosis while Circular Stapler is involved in colorectal anastomosis. Stapled anastomosis could be done whether during open surgery or laparoscopic surgery (Buunen et al., 2009)

Early detection of complications is the final important aspect of post-operative care in the early detection of complications. Elderly patients in particular are at increased risk for developing complications, mainly due to their reduced physiologic reserves. Extra efforts must be made to prevent potential complications and to identify actual complications as early as possible (Lees et al., 2009)

The aim of this work was to compare single layer, double layers and stapler intestinal anastomosis (Stomach, Stomach to small, small to small, small to large and large to large) in abdominal procedures and to evaluate the effectiveness of these procedures as regards to its integrity and complications including leakage.

\section{PATIENTS AND METHODS}

Prospective study carried out at Al-Azhar university hospitals and public health ministry hospitals starting from March 2018 on 50 patients presented with symptoms and signs suggestive for gastric operations, intestinal surgeries, resection and anastomosis.

\section{Inclusion criteria:}

Patients who have suggestions for gastrointestinal surgeries clinically, laboratory findings or by radiological diagnosis. 


\section{Exclusion criteria:}

No patient will be excluded.

Informed Consent: A written informed consent was obtained from each patient before he/she got enrolled into the study.

Ethical principles: This clinical trial was conducted in accordance with the principles laid down by the 18th World Medical Association (Helsinki, 2013) and all applicable amendments laid down by the World Medical Association and $\mathrm{ICH}$ guidelines for Good Clinical Practice.

Laws and regulations: This clinical trial was conducted in compliance with all international laws and regulations, and national laws and regulations of Egypt in which the clinical trial was performed, as well as any applicable guidelines.

\section{Statistical Analysis:}

Data were collected, revised, coded and entered to the Statistical Package for Social Science (IBM SPSS) version 23. The quantitative data were presented as mean, standard deviations and ranges when their distribution found parametric. Also, qualitative variables were presented as number and percentages. The comparison between two groups regarding qualitative data were done by using Chi-square test and Fisher exact test instead of Chisquare test when the expected count in any cell found less than 5. The comparison between two independent groups with quantitative data and parametric distribution were done by using Independent t-test. The confidence interval was set to $95 \%$ and the margin of error accepted was set to $5 \%$. So, the p-value was considered significant when P-value $>0.05$.

\section{RESULTS}

Our study was done on 50 patients, 30 female patients and 20 male patients on age ranging from 22 to 70 years. Study group was divided to two groups, traditional group (27 patients) and Stapled group (23 patients). This was a comparative study regarding comorbidities, intra-operative bleeding, time of operation, cost of operation and postoperative leakage. (Table1)

The present study showed high significance between two groups in intra- operative bleeding, time and cost of operation as $46 \%$ of patients suffered minimal to mild bleeding, high operation cost and less time of procedure while 54\% of patients suffered minimal to moderate intra-operative bleeding, lower operation cost and longer procedure time.

Study showed no significance between two groups in post-operative leakage as $11 \%$ of patients from traditional groups suffered leakage and $8.7 \%$ of stapled groups had leakage. 
Table (1): Demographic data and comparative studies regarding co-morbidities, intra-operative bleeding, time of operation, cost and post-operative leakage

\begin{tabular}{|l|l|l|}
\hline \multicolumn{2}{|c|}{ Parameters } & \multicolumn{1}{c|}{ Total no. = 50 } \\
\hline \multirow{2}{*}{ Age (years) } & Mean \pm SD & $45.58 \pm 11.10$ \\
& Range & $22-70$ \\
\hline \multirow{2}{*}{ Gender } & Female & $30(60.0 \%)$ \\
& Male & $20(40.0 \%)$ \\
\hline \multirow{2}{*}{ Co-morbidities } & No & $21(42.0 \%)$ \\
& Yes & $29(58.0 \%)$ \\
\hline Intra-operative & Minimal to mild & $23(46.0 \%)$ \\
bleeding & Minimal to moderate & $27(54.0 \%)$ \\
\hline \multirow{2}{*}{ Time of operation } & Long & $27(54.0 \%)$ \\
& Short & $23(46.0 \%)$ \\
\hline \multirow{2}{*}{ Cost } & Low & $27(54.0 \%)$ \\
& High & $23(46.0 \%)$ \\
\hline \multirow{2}{*}{ Leakage } & No & $45(90.0 \%)$ \\
& Yes & $5(10.0 \%)$ \\
\hline \multirow{2}{*}{ Study groups } & Traditional group & $27(54.0 \%)$ \\
& Stapled group & $23(46.0 \%)$ \\
\hline
\end{tabular}

Study showed significance between two groups in post-operative oral nutrition and discharge from hospital as patients underwent stapled anastomosis were allowed for oral nutrition 8 to 24 hours postoperatively and were discharged from hospital after 1 to 3 days, while patients underwent traditional anastomosis allowed for nutrition after 5 to 7 days post-operatively and were discharged from 5 to 10 days to home. There was no significance between two groups related to post-operative prolonged ileus, wound infection nor anastomotic stricture. (Table 2) 
Table (2): Comparison between Traditional and Stapled group

\begin{tabular}{|c|c|c|c|c|}
\hline \multicolumn{2}{|r|}{ Groups } & Traditional group & Stapled group & \multirow{2}{*}{$\begin{array}{c}\mathbf{P}- \\
\text { value }\end{array}$} \\
\hline \multicolumn{2}{|l|}{ Parameters } & No. $=27$ & No. $=23$ & \\
\hline \multirow{2}{*}{ Age (years) } & Mean \pm SD & $44.04 \pm 10.48$ & $47.39 \pm 11.76$ & \multirow[b]{2}{*}{0.291} \\
\hline & Range & $22-65$ & $25-70$ & \\
\hline \multirow{2}{*}{ Gender } & Female & $16(59.3 \%)$ & $14(60.9 \%)$ & \multirow{2}{*}{0.908} \\
\hline & Male & $11(40.7 \%)$ & $9(39.1 \%)$ & \\
\hline \multirow{2}{*}{ Co-morbidities } & No & $13(48.1 \%)$ & $8(34.8 \%)$ & \multirow{2}{*}{0.340} \\
\hline & Yes & $14(51.9 \%)$ & $15(65.2 \%)$ & \\
\hline \multirow[b]{2}{*}{$\begin{array}{l}\text { Intra-operative } \\
\text { bleeding }\end{array}$} & Minimal to mild & $0(0.0 \%)$ & $23(100.0 \%)$ & \multirow[b]{2}{*}{0.001} \\
\hline & $\begin{array}{l}\text { Minimal to } \\
\text { moderate }\end{array}$ & $27(100.0 \%)$ & $0(0.0 \%)$ & \\
\hline \multirow{2}{*}{ Time of operation } & Long & $27(100.0 \%)$ & $0(0.0 \%)$ & \multirow{2}{*}{0.001} \\
\hline & Short & $0(0.0 \%)$ & $23(100.0 \%)$ & \\
\hline \multirow{2}{*}{ Cost } & Low & $27(100.0 \%)$ & $0(0.0 \%)$ & \multirow{2}{*}{0.001} \\
\hline & High & $0(0.0 \%)$ & $23(100.0 \%)$ & \\
\hline \multirow{2}{*}{ Leakage } & No & $24(88.9 \%)$ & $21(91.3 \%)$ & \multirow{2}{*}{0.777} \\
\hline & Yes & $3(11.1 \%)$ & $2(8.7 \%)$ & \\
\hline \multirow{2}{*}{$\begin{array}{l}\text { Postoperative } \\
\text { bleeding }\end{array}$} & No & $24(88.9 \%)$ & $21(91.3 \%)$ & \multirow{2}{*}{0.777} \\
\hline & Yes & $3(11.1 \%)$ & $2(8.7 \%)$ & \\
\hline \multirow{2}{*}{ Wound infection } & No & $24(88.9 \%)$ & $18(78.3 \%)$ & \multirow{2}{*}{0.307} \\
\hline & Yes & $3(11.1 \%)$ & $5(21.7 \%)$ & \\
\hline \multirow{2}{*}{$\begin{array}{l}\text { Anastomotic } \\
\text { stricture }\end{array}$} & No & $26(96.3 \%)$ & $21(91.3 \%)$ & \multirow{2}{*}{0.459} \\
\hline & Yes & $1(3.7 \%)$ & $2(8.7 \%)$ & \\
\hline \multirow{2}{*}{ Prolonged ileus } & No & $21(77.8 \%)$ & $19(82.6 \%)$ & \multirow{2}{*}{0.670} \\
\hline & Yes & $6(22.2 \%)$ & $4(17.4 \%)$ & \\
\hline \multirow{2}{*}{$\begin{array}{l}\text { Postoperative oral } \\
\text { nutrition (hrs) }\end{array}$} & $(8-24)$ & $0(0.0 \%)$ & $21(91.3 \%)$ & \multirow{2}{*}{0.000} \\
\hline & $(120-240)$ & $27(100.0 \%)$ & $2(8.7 \%)$ & \\
\hline \multirow{2}{*}{$\begin{array}{l}\text { Discharge from } \\
\text { hospital }\end{array}$} & $(1-3)$ & $0(0.0 \%)$ & $21(91.3 \%)$ & \multirow{2}{*}{0.000} \\
\hline & $(5-10)$ & $27(100.0 \%)$ & $2(8.7 \%)$ & \\
\hline
\end{tabular}

\section{DISCUSSION}

This study compared between traditional and stapled groups of anastomosis in which there was significance between two groups in intraoperative bleeding, time and cost of operation as $46 \%$ of patients suffered minimal to mild bleeding, high operation cost and less time of procedure while 54\% of patients suffered minimal to moderate intra-operative bleeding, lower operation cost and longer procedure time (Choy et al., 2011)

Study showed high significance between two groups in post-operative oral nutrition and discharge from hospital as patients underwent stapled anastomosis were allowed for oral nutrition 8 to 24 hours postoperative and were discharged from hospital after 1 to 3 days while patients underwent traditional anastomosis were allowed for nutrition after 5 to 7 days postoperatively and were discharged from 5 to 10 days to home (Wang et al., 2012)

Study shows no significance between two groups related to post-operative prolonged ileus, wound infection nor anastomotic stricture (Zhong et al., 2010) 


\section{CONCLUSION}

Stapled gastrointestinal anastomosis consumes lesser time at operation room, less intraoperative bleeding, early recovery and oral nutrition of patients, but has higher cost. Traditional gastrointestinal anastomosis consumed longer time at operation room, relatively more intraoperative bleeding, late recovery and oral nutrition of patients but has lower cost. Both types of gastrointestinal anastomosis have the same postoperative co-morbidities.

Study's Limitations: This was a crosssectional study with inherent limitations of possible misclassification and ascertainment bias. In addition, the study was a single-center experience and, therefore, the results cannot be generalized to the general population.

\section{REFERENCES}

1. Bae KB, Kim SH, Jung SJ and Hong KH. (2010): Cyanoacrylate for colonic anastomosis; is it safe? Int J Colorectal Dis., 25 (5):601.

2. Bu and Ji J (2013): A Current view of Gastric cancer in china. Gastrointestinal cancer, 2(1):1-4.

3. Buunen M, Veldkamp R, Hop WC, Kuhry E, Jeekel J and Haglind E. (2009): Survival after laparoscopic surgery versus open surgery for colon cancer: long-term outcome of a randomised clinical trial. Lancet Oncol. 10(1):44-52.

4. Choy PY, Bissett IP, Docherty JG and Parry BR. (2011): Cochrane Database Syst Rev. Stapled Versus handsewn methods for ileocolic anastomosis; p.CD004320.

5. Ghaferi AA, Birkmeyer JD and Dimick JB. (2009): Variation in hospital mortality associated with inpatient surgery. N Engl J Med., 361(14):1368-1375.

6. Kaidar-Person O, Rosenthal RJ, Wexner SD, Szomstein S and Person B. (2008): Compression anastomosis: history and clinical considerations. Am J Surg., 195 (6):818-26.

7. Lees N, Hamilton M and Rhodes A. (2009): Clinical review: goal-directed therapy in high risk surgical patients. Crit Care, 13(5):231.

8. Wang JB, Fan JH, Liang H (2012): Attributable causes of esophageal cancer incidence and mortality in china. Plos One, 7: e42281.

9. Zhong XH, Gan AH and Jang B (2010): a demographic and anatomy survey. World $\mathbf{J}$ Gastroenterol,16:960-965. 


\section{در اسة المقارنة بين المفاغرة التقليدية و المفاغرة بالدباسه لجر احات المعده و الامعاء المهنه}

'أحمد عبدالعزيز عبد الغفار، 'وليد رأفت عبدالعاطي، 'حسام محمد بدري بسطاوي قسم الجراحة العامة، كلية الطب، جامعة الأزهر

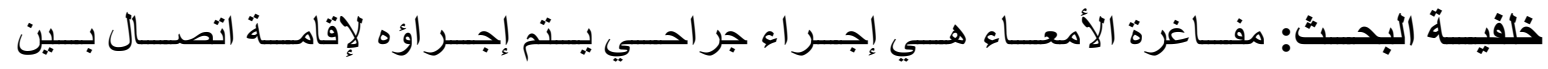

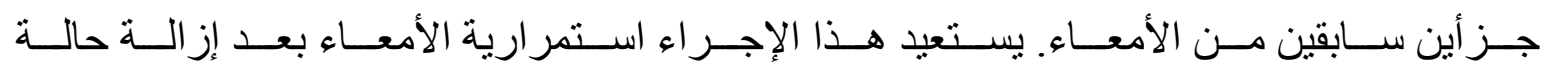

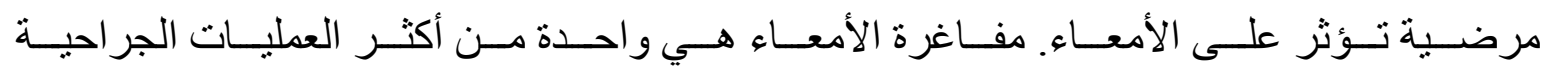

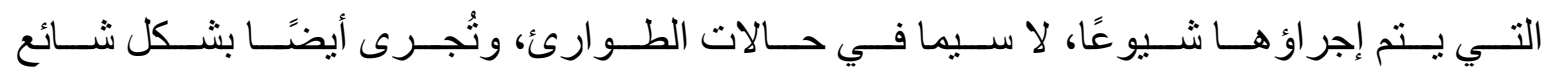

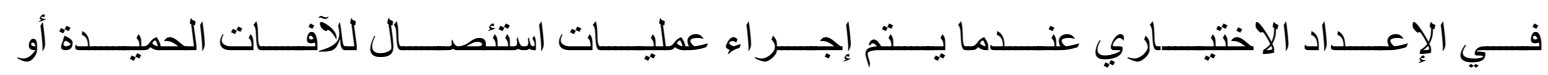
الخبيثة في الجهاز الهضمي.

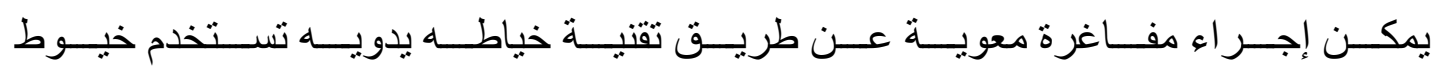

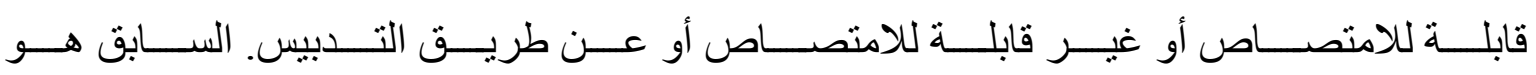

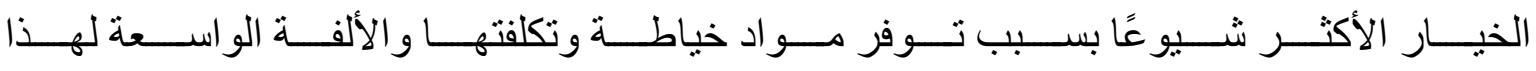

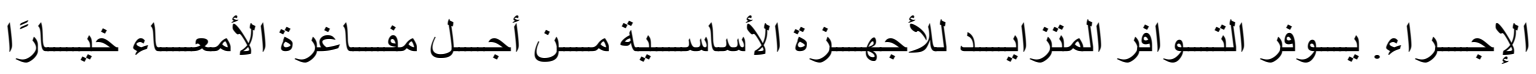


و التو افر المحدود و أقل معرفة.

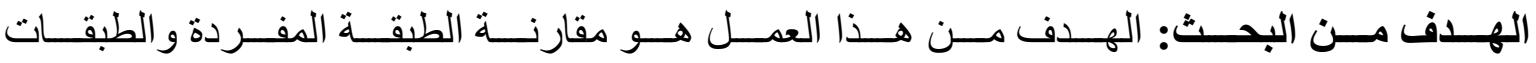

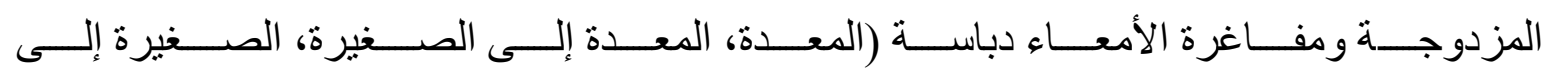

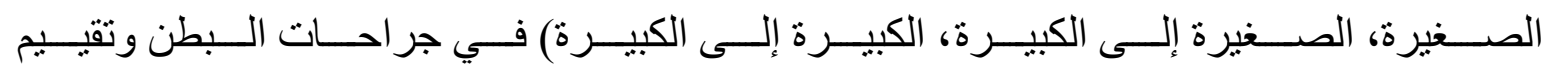
فعالية هذه الإجر اءات فيما يتعلق سلامتها و المضاعفات.

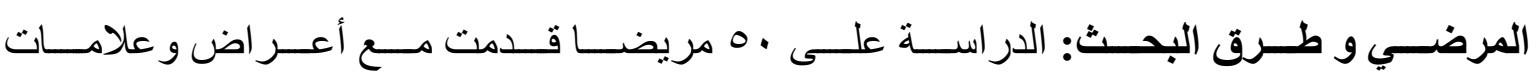

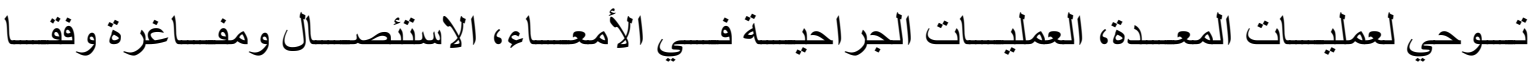

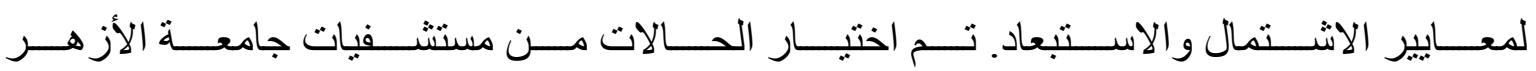

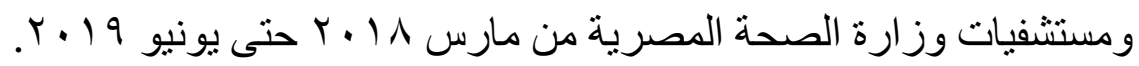




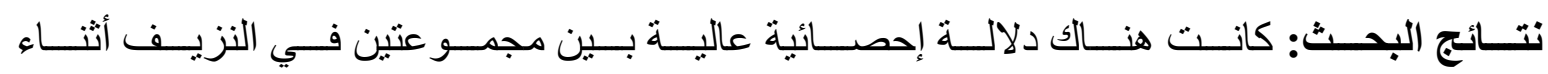

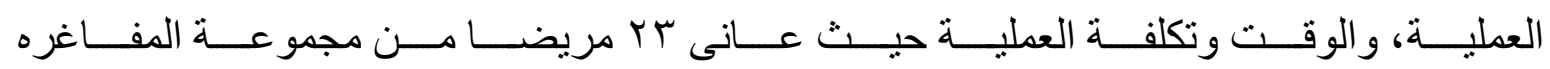

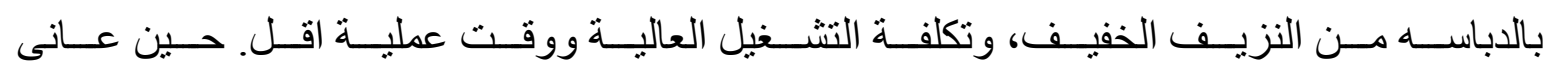

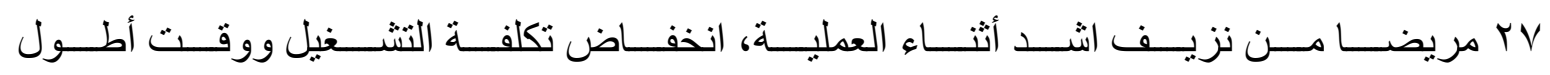

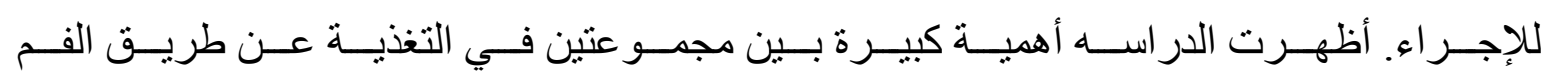

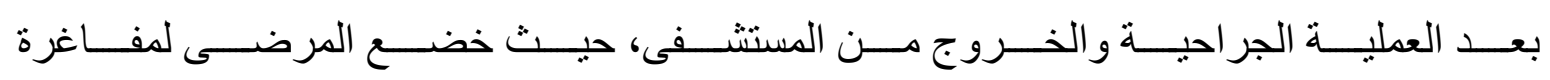







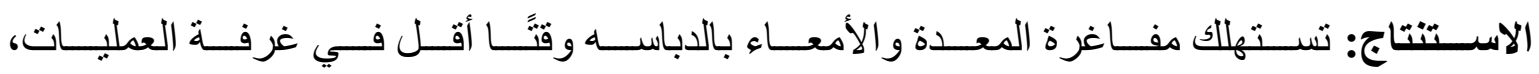

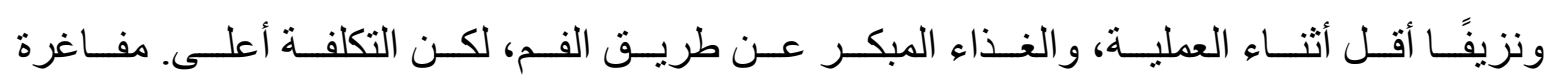

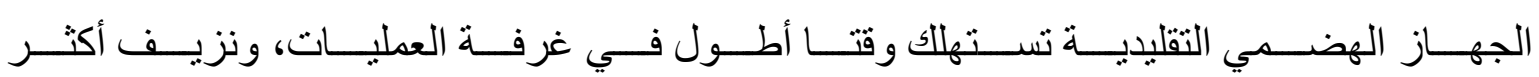

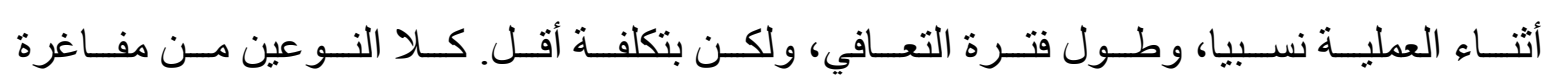
الجهاز الهضمي لديه نفس المضاعفات الوارده بعد العملية الجر احية. 